\title{
Photoactivation of a Substrate for Cell Adhesion under Standard
}

\author{
Fluorescence Microscopes \\ Jun Nakanishi, ${ }^{\dagger}$ Yukiko Kikuchi, ${ }^{\dagger}$ Tohru Takarada, ${ }^{*, \dagger}$ Hidekazu Nakayama, ${ }^{\ddagger}$ Kazuo \\ Yamaguchi, ${ }^{\ddagger}$ and Mizuo Maeda ${ }^{*, \dagger}$ \\ ${ }^{\dagger}$ Bioengineering Laboratory, RIKEN, 2-1 Hirosawa, Wako, Saitama 351-0198, Japan, and \\ ${ }^{\ddagger}$ Department of Materials Science, Faculty of Science, Kanagawa University, 2946 Tsuchiya, \\ Hiratsuka, Kanagawa 259-1293, Japan
}

\section{Supporting Information}


Contact angle measurements for the determination of the optimal UV irradiation time. Glass coverslips modified with silane coupling agents having caged carboxyl group exhibit decreases in contact angle by UV irradiation, which is corresponding to the photocleavage reaction. ${ }^{1}$ In order to determine the optimal irradiation time, the dependence of contact angle of the present substrate on UV irradiation time was evaluated. Cut pieces of a single glass coverslip chemically modified with NPE-TCSP were irradiated under the fluorescence microscope. The irradiated pieces were washed with methanol and chloroform, sonicated in chloroform for $10 \mathrm{~min}$, and then dried with nitrogen. Values of the contact angles of water in cosine were plotted against the duration of irradiation (Figure S1). In order to irradiate sufficient area for the contact angle measurement, a $5 \mathrm{X}$ objective lens was used in place of the 10X lens that had been used throughout the present study. The power of UV light using the 5X lens was one seventh of that using the $10 \mathrm{X}$ lens, as determined by a UIT-150 power meter equipped with UVD-S365 (Ushio). Therefore, the irradiation time of $2.5 \mathrm{~min}$ with the 10X lens in the cell adhesion studies corresponded to $18 \mathrm{~min}$ of irradiation with the $5 \mathrm{X}$ lens. The change in wettability of the substrate is nearly completed in this irradiation time.

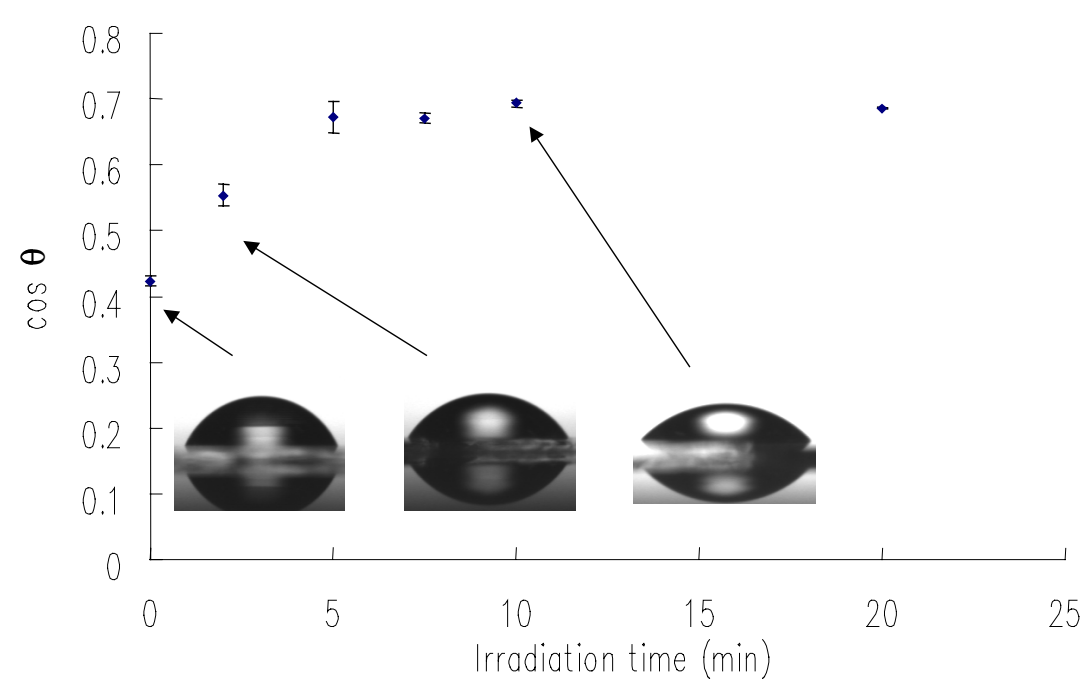

Figure S1. Effect of UV irradiation time on the contact angles of a glass coverslip modified with NPE-TCSP. Values of the contact angles of water in cosine were plotted against the duration of irradiation. The error bars represent standard deviations of measurements at different four points of a cut piece of a glass coverslip.

\section{Cell attachment onto a UV-irradiated region of a glass coverslip modified with a non-photolabile} alkylsiloxane. The photocleavage step is essential for the UV-directed formation of cell-adhesive regions. A control experiment with HEK293 cells was performed by using a substrate modified with a non-photolabile 2-(carbomethoxy)ethyltrichlorosilane $\left(\mathrm{CH}_{3} \mathrm{OCOCH}_{2} \mathrm{CH}_{2} \mathrm{SiCl}_{3}\right.$; Wako) under identical 
conditions with those of Figure 2b. No cell pattern was observed corresponding to the UV-irradiated region. (Figure $\mathrm{S} 2$ ).
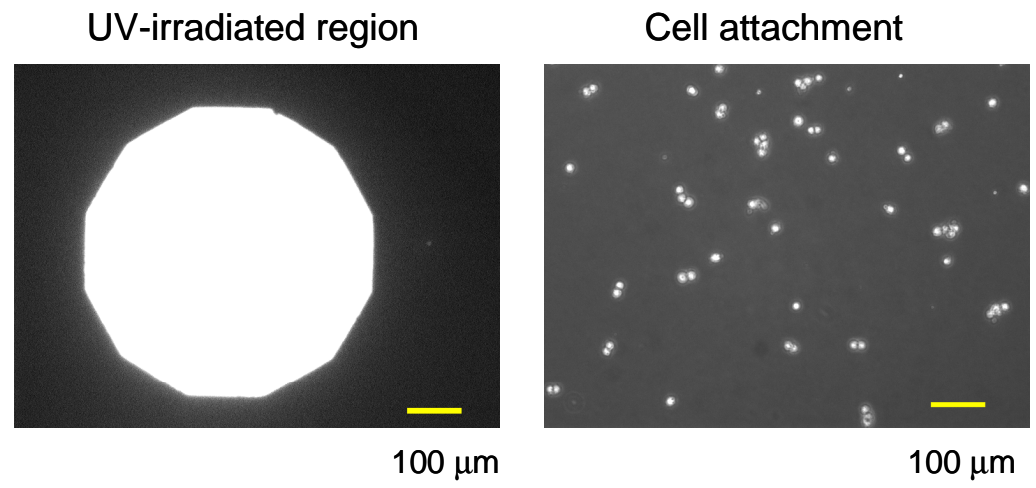

Figure S2. No cell pattern was observed corresponding to the UV-irradiated region (left) on a glass coverslip chemically modified with a non-photolabile alkylsiloxane. A phase-contrast image of HEK293 cells at $2 \mathrm{~h}$ after seeding (right).

Cell attachment onto a UV-irradiated region of a glass without an addition of fibronectin. An addition of fibronectin is essential for making UV-irradiated region cell-adhesive. A control experiment with HEK293 cells was performed by omitting fibronectin from the patterning procedure under the identical conditions with those of Figure $2 b$. Without an addition of fibronectin, less cells attached to the irradiated region compared to that using fibronectin (Figure S3). In addition, cells attached to this region did not spread (Figure S3c) because of weak cell adhesiveness to this region.

(a)

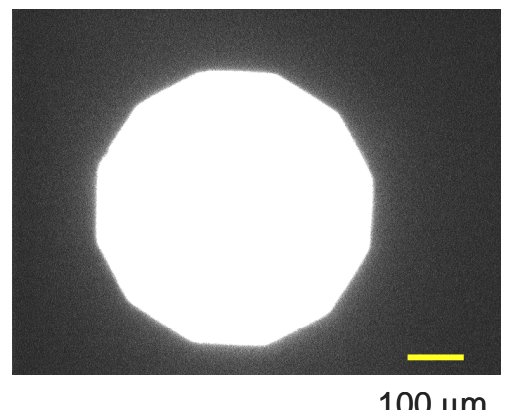

(b)

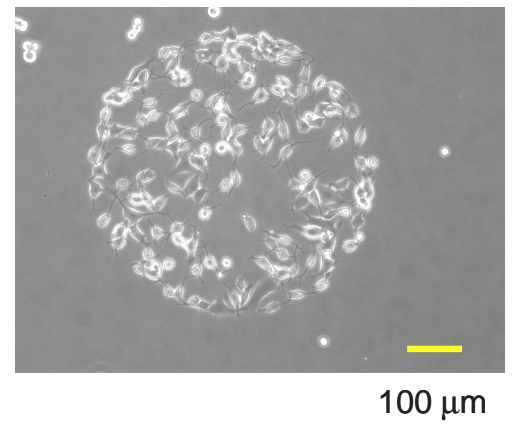

(c)

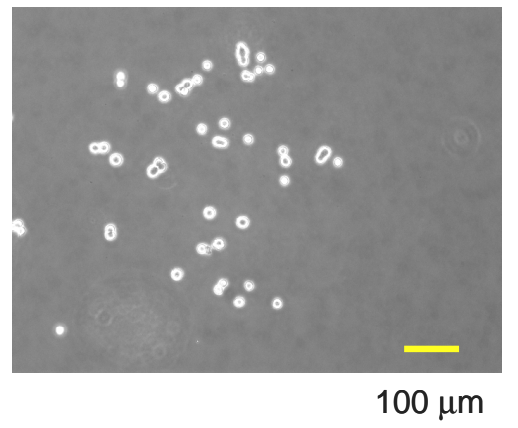

Figure S3. An addition of fibronectin is essential for forming cell-adhesive spots. (a) UV-irradiated region. (b, c) Phase-contrast images of HEK293 cells at $2 \mathrm{~h}$ after seeding. Attachment of HEK293 cells to UV-irradiated regions, where fibronectin was added (b) or not (c) after UV irradiation. 
Immunofluorescence study for the detection of surface proteins. Glass coverslips modified with NPE-TCSP were first coated with BSA by incubation in PBS containing $10 \mathrm{mg} / \mathrm{ml} \mathrm{BSA} \mathrm{for} 1 \mathrm{~h}$ at room temperature and irradiated for 2.5 min over a circular region under a fluorescence microscope. Then the substrate was soaked in PBS containing $25 \mu \mathrm{g} / \mathrm{ml}$ fibronectin for $30 \mathrm{~min}$ at room temperature. The proteins adsorbed on the surface before and after incubation with fibronectin were fixed with $2 \%$ paraformaldehyde, and were reacted with rabbit anti-BSA antibodies (Bethyl) and rabbit anti-fibronectin antibodies (Sigma), respectively. We used $0.3 \%$ casein as a blocking agent. Then the substrates were incubated with goat AlexaFluor 488 labeled anti-rabbit IgG (Molecular Probes). Fluorescence images were obtained using a 500AF24 excitation filter, a 500DRLP dichroic mirror, and a 545AF35 emission filter (OMEGA). As shown in Figure S4, BSA dissociated from the surface by UV irradiation, and the following addition of fibronectin resulted in its selective attachment to the region.

(a)

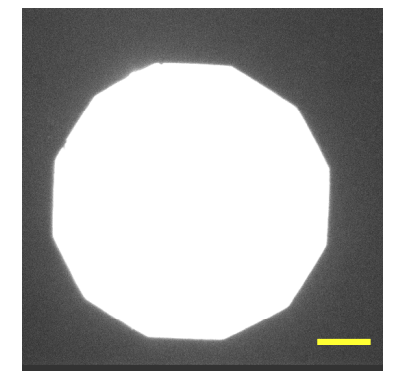

$100 \mu \mathrm{m}$ (b)

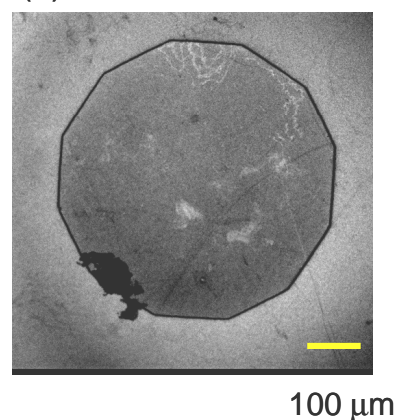

(c)

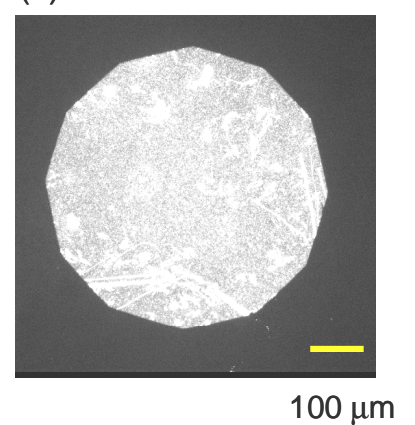

Figure S4. An immunofluorescence study for the detection of BSA and fibronectin on the surface of the substrate. (a) UV-irradiated region. (b) An immunofluorescence image of the substrate before incubating with fibronectin using anti-BSA. (c) An immunofluorescence image of the substrate after incubating with fibronectin using anti-fibronectin.

Cell culture. HEK293 cells (JCRB) and COS7 cells (RIKEN) were cultured in minimum essential medium Eagle (MEM; SIGMA) containing 10\% horse serum, $100 \mathrm{U} / \mathrm{ml}$ penicillin and $100 \mu \mathrm{g} / \mathrm{ml}$ streptomycin, and NIH3T3 (RIKEN) cells were cultured in Dulbecco's modified Eagle's medium (DMEM; SIGMA) containing $10 \%$ calf serum at $5 \% \mathrm{CO}_{2}$ in $37^{\circ} \mathrm{C}$.

Synthesis of 1-(2-nitrophenyl)ethyl 5-trichlorosilylpentanoate (NPE-TCSP). NPE-TCSP was synthesized using a method similar to that reported previously. ${ }^{2}$ Briefly, 4-pentenoic acid was coupled with 2-nitrobenzyl alcohol in the presence of 1-ethyl-3-(3-dimethylaminopropyl)carbodiimide hydrochloride and 4-dimethylaminopyridine, which gave 1-(2-nitrophenyl)ethyl 4-pentenoate. The 
obtained compound was purified by silica gel column chromatography. The purified ester was reacted with trichlorosilane in the presence of $\mathrm{H}_{2} \mathrm{PtCl}_{6} \cdot 6 \mathrm{H}_{2} \mathrm{O}$ as a catalyst, and the final product was isolated by vacuum distillation. ${ }^{1} \mathrm{H} \mathrm{NMR}$ (400 MHz, $\left.\mathrm{CDCl}_{3} / \mathrm{TMS}\right): \delta$ 7.41-7.94 (m, 4H, aromatic), 6.33 (q, $J=6.6 \mathrm{~Hz}$, $1 \mathrm{H}$, methine), 2.35-2.40 (m, 2H, methylene), 1.70-1.75 (m, 2H, methylene), $1.65(\mathrm{~d}, J=6.6 \mathrm{~Hz}, 3 \mathrm{H}$, methyl), 1.56-1.63 (m, 2H, methylene), 1.38-1.42 (m, 2H, methylene). $\mathrm{IR}(\mathrm{NaCl}): 1738 \mathrm{~cm}^{-1}(\mathrm{C}=\mathrm{O})$, 1528 and $1351 \mathrm{~cm}^{-1}\left(\mathrm{NO}_{2}\right)$. Elemental Analysis: Calcd for $\mathrm{C}_{13} \mathrm{H}_{16} \mathrm{NO}_{4} \mathrm{Cl}_{3} \mathrm{Si}: \mathrm{C}, 40.59 ; \mathrm{H}, 4.19 ; \mathrm{N}, 3.64$; O, 16.63; Si, 7.3; Cl, 27.65. Found: C, 40.17; H, 4.01; N, 3.49.

Surface treatment and cell seeding. Glass coverslips $(0.12-0.17 \mathrm{~mm}$ thick; Matsunami) were treated with the mixed solution of sulfuric acid and hydrogen peroxide $(7: 3, v / v)$ for $1 \mathrm{~h}$ at $100^{\circ} \mathrm{C}$, washed with distilled water, and then dried with nitrogen. Dry benzene solution of NPE-TCSP containing the glass coverslips was refluxed for $1 \mathrm{~h}$. The coverslips were washed with methanol and chloroform, sonicated in chloroform for $10 \mathrm{~min}$, and then dried with nitrogen. The coverslips were then placed on the bottom of a glass-bottom dish (MatTek), sterilized with ethanol, and soaked in PBS containing $10 \mathrm{mg} / \mathrm{ml} \mathrm{BSA}$ (Wako) for $1 \mathrm{~h}$ at room temperature. UV irradiation was performed using a Carl Zeiss Axiovert 200 fluorescence microscope equipped with a $100 \mathrm{~W}$ mercury arc lamp using an excitation filter (330 $\pm 40 \mathrm{~nm}$; OMEGA) and a 10X Plan Apochromat objective lens (Zeiss). A photomask printed on a transparency ${ }^{3}$ was inserted at the field diaphragm slider of the microscope. After irradiation, the buffer was changed to PBS containing $25 \mu \mathrm{g} / \mathrm{ml}$ fibronectin (BD Biosciences), and the substrates were incubated for $30 \mathrm{~min}$ at room temperature. Cells (4-8 × $10^{5}$ cells/dish) were seeded onto the substrates in MEM, and incubated for $2 \mathrm{~h}$ before changing the medium to that containing serum. Before seeding the second cells, the substrate was incubated overnight, and then irradiated in the close proximity to cells attached beforehand. The cells stained with CellTracker Green CMFDA (Molecular Probes) were allowed to attach for $3 \mathrm{~h}$ to the substrates in the complete medium containing $25 \mu \mathrm{g} / \mathrm{ml}$ fibronectin.

\section{References}

(1) Zhao, B.; Moore, J. S.; Beebe, D. J. Science 2001, 291, 1023-1026.

(2) Yamaguchi, K.; Kitabatake, T.; Izawa, M.; Fujiwara, T.; Nishimura, H.; Futami, T. Chem. Lett. 2000, 29, 228-229.

(3) Duffy, D. C.; McDonald, J. C.; Schueller, O. J. A.; Whitesides, G. M. Anal. Chem. 1998, 70, 4974-4984. 